University of Nebraska - Lincoln

DigitalCommons@University of Nebraska - Lincoln

U.S. Navy Research

U.S. Department of Defense

2007

Neglect of Plasmodium vivax malaria

J. Kevin Baird

ALERTAsia, jkevinbaird@yahoo.com

Follow this and additional works at: https://digitalcommons.unl.edu/usnavyresearch

Baird, J. Kevin, "Neglect of Plasmodium vivax malaria" (2007). U.S. Navy Research. 96.

https://digitalcommons.unl.edu/usnavyresearch/96

This Article is brought to you for free and open access by the U.S. Department of Defense at DigitalCommons@University of Nebraska - Lincoln. It has been accepted for inclusion in U.S. Navy Research by an authorized administrator of DigitalCommons@University of Nebraska - Lincoln. 


\section{Neglect of Plasmodium vivax malaria}

\section{J. Kevin Baird}

ALERTAsia Foundation, Jalan Diponegoro No.69, Menteng, Jakarta, Pusat 10430, Indonesia

\begin{abstract}
Plasmodium vivax infects $130-435$ million of the 2.6 billion people living at risk of infection. Recent studies suggest that vivax malaria can become lethal in a similar way to severe falciparum malaria. First-line therapies remain unchanged after 50 years. Despite evidence of failing chloroquine efficacy, little work has assessed the problem or explored alternative therapies. Primaquine treatment, the only therapeutic option against relapse, might also be failing. No licensed primary chemoprophylactic agent protects travelers from relapse. Misdiagnosis of species now affects clinical decisions resulting in inadequate therapy for $P$. falciparum and $P$. vivax. All of these factors demonstrate the lack of research on $P$. vivax.
\end{abstract}

\section{Investment and therapeutic options}

Research investments reach across a broad spectrum of inquiry into the physiological, clinical, social and economic consequences of infectious disease burdens, as well as their treatment, prevention and control. Successful clinical management of potentially dangerous and prevalent infections surely represents the highest research priority. This review treats research on therapies as the principal indicator of broader research investments.

The quality of available therapies for dangerous infections reflects investments made in research on these diseases. The quality of therapy can be defined as the reliability of carefully analyzed clinical research demonstrating good safety, tolerability, efficacy and effectiveness. An even higher standard of quality provides understanding of metabolism, mechanisms of both therapeutic action and toxic side effects, and mechanisms of resistance by the target organisms. These facets of quality allow us to move forward with better therapies and, in turn, provide clinicians with options and a basis for making sound therapeutic management decisions. In other words, the hallmarks of infections that have received adequate attention and investment in research are the availability of drugs of predictable performance and of therapeutic options in the face of predictable or realized failure.

Against this backdrop Plasmodium vivax might be considered perhaps the most neglected, potentially dangerous and highly prevalent infection. The two current frontline therapies for $P$. vivax, chloroquine (CQ) and primaquine $(\mathrm{PQ})$, have been in use since 1946 and 1950, respectively. These therapies are failing, but the risk of failure with either drug is not generally known. The mechanism of activity of either drug and the mechanisms of resistance remain unknown. The metabolism of $\mathrm{PQ}$ is little understood.

Corresponding author: Baird, J.K. (kbaird@alertasia.org).
PQ destroys red blood cells with an inborn deficiency of glucose-6-phosphate dehydrogenase (G6PD) - a disorder linked with endemic malaria and most prevalent where the drug is most needed - but the mechanism of toxicity or the metabolite responsible for it is unknown. There are some poorly characterized alternatives for $\mathrm{CQ}$, and none for $P Q$. The strikingly poor quality of drugs available to treat vivax malaria reflects a lack of research investment in this infection.

If the marker of quality of therapeutics is applied to $P$. falciparum, the far more substantial investment in research on this parasite is evident. The past ten years have seen a much-needed and overdue proliferation of well-characterized therapeutic options for falciparum malaria. No one can argue against the higher research priority placed upon falciparum malaria therapies, given its greater lethality and perhaps prevalence. However, seeing the investment in treatment of falciparum malaria as directly linked and applicable to the problem of therapy of vivax malaria does not stand scrutiny. No fact supports this argument more clearly than the current state of therapeutic options for vivax malaria, which is detailed in this review.

\section{A highly prevalent and potentially dangerous infection}

Diseases that are highly prevalent but benign or dangerous but exceedingly rare can reasonably merit little research investment. However, Plasmodium vivax is neither rare nor benign. It occurs throughout the tropics, except in western and central sub-Saharan Africa where the absence of Duffy factor on the surface of red blood cells largely protects those populations. Guerra et al. [1] recently reported estimates of people living at risk of falciparum and vivax malaria at 2.5 and 2.6 billion people, respectively. Hay et al. [2] estimated 130-435 million infections by $P$. vivax, in contrast to the more widely cited figure of $70-80$ million annual infections [3]. At even the lower estimate, this roughly equals the disease burden of dengue fever and exceeds the disease burden of typhoid by about fivefold.

It has long been considered that vivax malaria is rarely fatal, and if it is fatal, it is considered to almost always be a consequence of rupture of the spleen [4]. Few texts attribute to $P$. vivax the syndromes occurring in severe and complicated $P$. falciparum malaria. However, recent studies using PCR diagnostic technologies revealed that patients diagnosed with vivax malaria and having cerebral malaria, acute respiratory distress syndrome (ARDS), liver dysfunction and renal failure had no evidence of falciparum malaria [5-8]. Table 1 summarizes 108 cases of severe and complicated vivax malaria since 1998, 17 of 
Table 1. Reports of severe and complicated $P$. vivax malaria since 1998

\begin{tabular}{|c|c|c|c|c|c|}
\hline Location & Year & No. of cases & Presentation & Fatal cases & Refs \\
\hline India & 2003 & $\begin{array}{l}11 \\
\text { adults }\end{array}$ & $\begin{array}{l}\text { Renal failure }=4 \\
\text { Jaundice }=4 \\
\text { ARDS }=3 \text { ( } 1 \text { fatal) } \\
\text { Cerebral = } 3 \text { ( } 1 \text { fatal) }\end{array}$ & 2 & {$[5]$} \\
\hline Pakistan & 2000 & 1 adult & Cerebral & 0 & {$[6]$} \\
\hline Venezuela & 2005 & 1 adult & ARDS & 0 & [7] \\
\hline India & 2006 & 1 adult & ARDS & 0 & {$[8]$} \\
\hline Afghanistan & 2004 & 1 adult & ARDS & 0 & [9] \\
\hline Singapore & 2003 & 2 adults & ARDS (fatal) & 1 & [10] \\
\hline Columbia & 1998 & 1 adult & ARDS & 0 & [11] \\
\hline Malaysia & 2003 & 2 adults & $\begin{array}{l}\text { ARDS }=1 \\
\text { DIC }^{a} / \text { Renal Failure }=1 \text { (fatal) }\end{array}$ & 1 & [12] \\
\hline India & 1999 & 2 & Renal failure $=2$ & $?$ & [13] \\
\hline India & 2002 & 16 & Renal failure $=16$ & 3 & [14] \\
\hline Turkey & 2005 & 1 child & Convulsions & 0 & [15] \\
\hline Indonesia & 2000 & $\begin{array}{l}21 \text { children } \\
17 \text { adults }\end{array}$ & $\begin{array}{l}\text { Cerebral = } 3(2 \text { fatal }) \\
\text { Siezures }=2(1 \text { fatal }) \\
\text { Anemia }=24 \\
\text { Hyperparasitemia = } 1 \\
\text { Renal failure }=4 \\
\text { Liver dysfunction = } 10 \text { (3 fatal) } \\
\text { Acidosis }=3(1 \text { fatal }) \\
\text { ARDS }=2(1 \text { fatal }) \\
\text { Cardiac arrest }=1 \text { (fatal) }\end{array}$ & 9 & [16] \\
\hline Afghanistan & 2003 & 1 adult & ARDS & 0 & [17] \\
\hline India & 2000 & 22 & $\begin{array}{l}\text { Liver dysfunction = } 8 \\
\text { Cerebral = } 1 \text { (fatal) } \\
\text { Anemia }=8 \\
\text { Thrombocytopenia = } 4 \\
\text { Pancytopenia = } 1\end{array}$ & 1 & [18] \\
\hline Brazil & 2000 & 1 adult & Thrombocytopenia & 0 & [19] \\
\hline New Guinea & 2000 & 1 adult & ARDS & 0 & [20] \\
\hline India & 1998 & 1 adult & Thrombocytopenia & 0 & [21] \\
\hline Kenya & 2004 & 1 adult & Splenic rupture & 0 & {$[22]$} \\
\hline Turkey & 2003 & 2 adults & Splenic rupture & 0 & [23] \\
\hline India & 2002 & 1 adult & ARDS & 0 & [24] \\
\hline India & 2006 & 1 child & Renal failure & 0 & [25] \\
\hline Total & & & & 17 & \\
\hline
\end{tabular}

${ }^{\mathrm{a} D I C}$, disseminated intravascular coagulation.

which proved fatal [5-25], and only two reports of a total of three patients with ruptured spleens, who all survived [22,23]. A 2004 review of the literature [23] reports that only 11 well-documented cases of splenic rupture in vivax malaria were published in the English medical literature since 1960. Ruptured spleen is either tremendously underrepresented in the medical literature, or it is a minor contributor to the spectrum of severe disease caused by vivax malaria. A recent report by Anstey et al. [26] describes lung injury among 50 patients with vivax malaria, and these authors report findings suggestive of parasite adhesion within pulmonary microvasculature.

A retrospective analysis of nearly 6000 hospital admissions for malaria over three years at Jayapura in Papua, Indonesia revealed that a third of patients had a diagnosis of $P$. vivax (two-thirds of those with monoinfections) by microscopy [16]. In that setting, almost all diagnosed malaria was managed on an outpatient basis, and only the significantly ill were admitted. Among the 1135 patients admitted with a diagnosis of vivax malaria, 38 were classified as having severe malaria (predominantly cerebral malaria), ARDS, liver dysfunction or renal failure. The $25 \%$ case fatality rate with a diagnosis of vivax malaria and a classification of severe disease was identical to those among similar patients with falciparum malaria [16].
Ruptured spleen was not reported in any of the patients at Jayapura, despite 1952 admissions with a diagnosis of $P$. vivax (including 817 mixed infection diagnoses). Syndromes more closely resembling severe and complicated falciparum malaria dominated presentations of severe disease among patients with a microscopic diagnosis of vivax malaria.

All of the reports of severe and complicated vivax malaria described in Table 1 apart from five [5-8,11] lack evidence ruling out cryptic falciparum malaria or inaccurate microscopic diagnoses. Clinicians and laboratory workers managing severely ill patients in endemic areas rarely have the advantage of PCR diagnostics, and presentation of cerebral malaria, ARDS, liver dysfunction and renal failure often leads to the presumptive diagnosis of severe falciparum malaria. Even if the microscopist reports a parasitemia of $P$. vivax, the absence of $P$. falciparum in the smear might be dismissed either as a lack of expertise at the microscope (mixed infections are notoriously difficult to detect) or as sequestration of $P$. falciparum. The investigators for most of the reports summarized in Table 1 apparently overcame this bias and reported vivax malaria as the causative agent. Prospective studies using PCR diagnostics of severely ill malaria patients are required to gauge the true risk of severe 
and fatal disease with vivax malaria. Perhaps more importantly, such studies must also rule out other infections likely to occur in a given area, for example bacterial meningitis, typhus, leptospirosis and dengue.

Well-documented studies reinforce the perception that vivax malaria is a relatively benign infection. Vivax malaria has been thoroughly studied in the clinical setting, albeit most often with a narrow range of strains represented, along with prompt diagnosis and treatment precluding serious disease [27,28]. Moreover, deaths due to $P$. vivax malaria among travelers occur rarely compared with those due to $P$. falciparum [29-31]. Finally, epidemic $P$. falciparum carries the well-known risk of high mortality, but there is no such record for epidemic $P$. vivax.

Most of what is known about morbidity and mortality linked to vivax malaria does not address settings of chronic and perhaps inadequately treated $P$. vivax malaria. Prevalent underlying disease states, like coinfections and nutritional deficiencies, add further uncertainty. The available data on severe $P$. vivax malaria suggest that there are conditions in which this parasite becomes lethal in a manner strikingly similar to that of $P$. falciparum. Many of the patients included in Table 1 come from settings where repeated exposures and relapse are likely, as well as risk for coinfection and poor nutrition. In the specific instance of the island of New Guinea, dominant resistance to $\mathrm{CQ}$ and to $\mathrm{PQ}$ (see below) may contribute to risk of severe disease.

The perception of vivax malaria as relatively benign may stem not only from an incomplete representation of settings of infection and disease, but perhaps also from an incomplete understanding of the taxonomy of the species. Some workers suggest that $P$. vivax is a complex of species [32]. Studies of naturally occurring morbidity and mortality caused by chronic exposure, inadequate therapy and relapse need to be done, particularly those supported with autopsy findings and thorough investigation of parasite genotypes.

\section{Failing chloroquine therapy}

Chloroquine has been first-line therapy for $P$. vivax since 1946. Although as little as $0.3 \mathrm{~g}$ CQ routinely cured CQsensitive $P$. vivax, the experts made no distinction between $P$. vivax and $P$. falciparum in recommending $1.5 \mathrm{~g}$ total adult dose for treatment of acute attacks of malaria [33]. This might, in part, explain the relatively late first-known appearance of CQ-resistant $P$. vivax in 1989 from Papua New Guinea [34]. The exquisite sensitivity of gametocytes of $P$. vivax to $\mathrm{CQ}$ (and the absence of such sensitivity in $P$. falciparum) might also help explain the prolonged effectiveness.

Studies in eastern Indonesia during the 1990s revealed a severe CQ resistance problem, with most treatments ending in failure [33]. More recent studies in eastern Indonesia reported essentially similar findings [35]. Surveys elsewhere in Indonesia showed low risk of failure in the western provinces and intermediate risk towards the center of the archipelago [33]. Case reports of resistance appeared from other countries in the region [33]. However, sustained survey work measuring risk of $\mathrm{CQ}$ failure in vivax malaria has been done only in Indonesia, Thailand and India. In Thailand, a thorough examination of several thousand infections revealed almost no evidence of resistance [36-40]. Among 869 subjects evaluated in three separate studies in India, none showed evidence of resistance to CQ [41-43]. Survey work in Turkey $[44,45]$ and in Vietnam [46] showed moderate levels of resistance (15\% and $22 \%$ failure, respectively). A recent study in northeastern Indonesian New Guinea, where failure for CQ alone approaches $100 \%$, showed only $18 \%$ failure when CQ was supplemented with PQ [47]. Surveys from South America show from no resistance to low levels of resistance $[48,49]$. The problem of CQ-resistant $P$. vivax thus appears to have originated on the island of New Guinea and might be spreading outwards, but not yet within the reach of Thailand or India (see Table 2).

The reporting of systematic surveys to gauge the risk of CQ failure cannot be considered adequate in any region, including southeast Asia, and information from other regions is limited to only a few case reports - relatively little such risk assessment work appears to be in progress. Despite compelling evidence of failing efficacy, almost no research is under way to ascertain the risk of therapeutic failure of the first-line therapy for a potentially lethal infection that threatens 2.6 billion people.

\section{Effective therapies for chloroquine-resistant $\boldsymbol{P}$. vivax}

A few reports describe the efficacy of approved drugs for the treatment of $P$. vivax [50-53], and some reports describe treatments for CQ-resistant $P$. vivax [54-56]. Mefloquine (MQ) combined with $\mathrm{PQ}$ was effective in Papua, Indonesia (98\% efficacy) [47], and CQ combined with $\mathrm{PQ}$ was much more effective than $\mathrm{CQ}$ alone [47,54]. Some work in primate models also showed good efficacy of both MQ and the experimental 8-aminoquinoline, tafenoquine [57-59]. The failure to achieve continuous culture of $P$. vivax severely constrains the investigation of effective therapies, leaving clinical trials in humans and primate models as the only options for exploring alternatives. The expense and risk of such work usually requires solid preclinical studies as a foundation. Recent improvements with in vitro assays of drug activity against $P$. vivax (a rare example of a significant advance in research on this parasite) [60-63] at least offer the means of investigation of therapies in which the parasite can be obtained with relative ease. Despite evidence of resistance to $\mathrm{CQ}$, and a reasonable forecast of further deterioration, clinical investigation of alternative treatments for vivax malaria resistant to $\mathrm{CQ}$ rarely occurs.

\section{The puzzle of primaquine therapy}

No standard drug for an infection can be more shrouded in mystery than PQ. Despite more than 50 years of continuous use in millions of people annually as the only drug available for its therapeutic indication, it is not known how PQ acts, how it should be taken, or if it acts when taken as directed [64].

PQ generates a complex mix of metabolites, each exhibiting often sharply distinct chemical and biological activities [65]. Which of these metabolites actually occur in the human liver and participate in killing hypnozoites, and how, is not clear. Nor is it clear which metabolites account 
Table 2. Surveys for chloroquine-resistant $\boldsymbol{P}$. vivax since $\mathbf{2 0 0 0}$

\begin{tabular}{|c|c|c|c|c|}
\hline Location & Year & Subjects (n) & Resistant (\%) & Refs \\
\hline Indonesia & 2004 & 40 & 65 & [35] \\
\hline Turkey & 2004 & 91 & 22 & [44] \\
\hline Indonesia ${ }^{a}$ & 2000 & 60 & 18 & [47] \\
\hline Vietnam & 2001 & 113 & 16 & [46] \\
\hline Turkey & 2001 & 112 & 15 & [45] \\
\hline Peru & 2001 & 177 & 2 & [48] \\
\hline India & 2004 & 287 & 0 & [41] \\
\hline Thailand $^{\mathrm{a}}$ & 2004 & 31 & 0 & [39] \\
\hline India ${ }^{a}$ & 2004 & 102 & 0 & [42] \\
\hline Colombia $^{a}$ & 2004 & 210 & 0 & [49] \\
\hline Thailand & 2003 & 161 & 0 & [39] \\
\hline India & 2001 & 480 & 0 & [43] \\
\hline
\end{tabular}

${ }^{a}$ Chloroquine combined with primaquine (greater efficacy).

for the hemolytic toxicity of the drug to people with G6PD deficiency. The largely hypothetical 6-methoxy metabolites of $\mathrm{PQ}$ do exhibit relatively strong activity against $P$. berghei liver stages [66], and when present in an environment favoring oxidized species (like redox-challenged G6PDdeficient red blood cell cytoplasm) become potentially toxic membrane disruptors $[67,68]$.

Setting aside the unknowns of metabolism, the pharmacokinetics of $\mathrm{PQ}$ is fairly well understood [69]. It is highly water soluble, rapidly absorbed and almost completely eliminated within $24 \mathrm{~h}$. Its peak plasma levels occur within just an hour or two, and plasma levels drop by a half within two hours. The pharmacokinetic profile of a standard 14 day regimen resembles uniform fence posts 14 independent spikes of presumably therapeutic levels of the drug. Preclinical and clinical studies revealed something unusual about these spikes - the sum of the areas under the curves (total dose) determined therapeutic efficacy independently of the dosing schedule [64,70]. If the daily dose of PQ is doubled and given for only 7 days, then it is equally effective. A 1.5-strength dose administered weekly over 8 weeks is effective too. As long as the sum length of the height of the 'fence posts' is the same (i.e. total dose), their individual height or space between them does not seem to affect the efficacy. The effect of $P Q$ on the parasite seems to be cumulative. The mystery of this phenomenon almost certainly lies in our almost complete lack of understanding of the physiology of hypnozoites.

A series of clinical trials in the 1950s reported findings that challenged the notion that $\mathrm{PQ}$ is effective at all when given as monotherapy [71,72]. When challenged with sporozoites of the Chesson strain, volunteers were given either 210 or $315 \mathrm{mg} \mathrm{PQ}$, either concurrently with standard CQ or quinine (QN) therapy, or after completing $\mathrm{QN}$ therapy. In effect, the investigators used combined therapy (CQ plus $\mathrm{PQ}$ or $\mathrm{QN}$ plus $\mathrm{PQ}$ ) or two independent monotherapies (QN followed by PQ). At both of the total doses of PQ, QN therapy followed by $\mathrm{PQ}$ resulted in $80 \%$ relapse rates, whereas the combined therapies gave essentially effective cures. The participation of QN and CQ in the activity of PQ seems the most likely explanation for these findings, even though neither drug has any known effect on liver stages when given as monotherapy against blood stages. PQ might require a companion drug to prevent relapse by $P$. vivax. The good efficacy of $\mathrm{PQ}$ alone as a causal prophylactic [73,74] does not necessarily run counter to this evidence - daily $\mathrm{PQ}$ for primary prophylaxis almost certainly prevents the formation of hypnozoites rather than kills them.

The efficacy of $\mathrm{PQ}$ for preventing relapse is not understood. Definitive experimental challenge trials evaluating this activity have not been done in over 50 years. There is no widely accepted method for measuring the efficacy of $\mathrm{PQ}$ in clinical trials, and such measurements present onerous technical, logistical and ethical barriers. Except for a few rare exceptions, the trials are not done. PQ is the only drug available for preventing debilitating and possibly lethal relapses, and it is not known whether PQ is effective.

\section{Preventing $\boldsymbol{P}$. vivax}

Every randomized, placebo-controlled trial of drugs for the prevention of malaria in travelers in the past 20 years has failed to address efficacy against late relapse by $P$. vivax. These trials tend to focus on demonstrating efficacy against $P$. falciparum while traveling. Indeed, study subjects are almost always residents of highly endemic areas, a fact driven by sample size and attack rate issues. The effect on late relapse is often deemed a separate issue covered by the practice of terminal prophylaxis with $\mathrm{PQ}$, that is, presumptive standard therapy immediately following exposure (synonymous with post-exposure treatment or PET) [74]. Separating these issues has practical validity; however, one gets back to the issue of whether the presumptive therapy provides protection against relapsing vivax malaria in travelers. Schwartz and colleagues [75,76] looked at the effectiveness of various regimens of prophylaxis in Israeli travelers. Suppressive prophylaxis (the standards such as MQ or doxycycline) routinely failed to prevent late relapses of $P$. vivax, despite the prescribed use of $\mathrm{PQ}$ terminal prophylaxis. $\mathrm{PQ}$ as primary prophylaxis might be the only tool available that protects travelers from vivax malaria. Although now recommended by the US Centers for Disease Control and Prevention (CDC) and similar agencies of other governments, the current US registered label for $\mathrm{PQ}$ does not include an indication for this use [74]. Despite significant risk of $P$. vivax relapse among travelers, no currently approved drug or combination of drugs is known to be effective in preventing this risk. The only drug known to be effective, $\mathrm{PQ}$, is not licensed for this use.

\section{Correct diagnosis of $\boldsymbol{P}$. vivax}

The successful development and distribution of the artemisinin-based combined therapies (ACT) for treatment of $P$. falciparum and the almost universal continuing use of CQ for vivax malaria create an important need for reliable diagnostic methods. Patients who have $P$. falciparum malaria that is diagnosed as vivax malaria might receive ineffective therapy. The health or even life of a patient might hinge upon the competency of the microscopist making the diagnosis.

Diagnosis of malaria by microscopy has been almost completely neglected since the heyday of the Global Eradication Campaign. Most microscopists working in clinics, hospitals and even research institutions received their training in school, and perhaps have been through refresher training. However, there is no standard method 
for measuring the competency of microscopists. In the field, the reliability of microscopists is usually measured by age and experience, simply because no other useful metric exists.

How often is $P$. falciparum misdiagnosed as $P$. vivax? The risk of a potentially grave error appears high even for expert microscopists. Mayxay et al. [77] found $8 \%$ of P. vivaxinfected Thai patients in Bangkok treated with CQ later developed falciparum malaria. Studies in Asia and the Americas typically report $13 \%-19 \%$ of microscopically $P$. vivax-positive specimens also contained $P$. falciparum detected by PCR assay [78]. Among well-trained clinical malaria microscopists in Thailand, 61 of 446 (14\%) true $P$. falciparum infections were diagnosed as $P$. vivax malaria [79]. During refresher training of 223 practising microscopists in Indonesia over 15 years, the error rate for species diagnosis of $P$. falciparum was $23 \%$ (K.B., unpublished).

In the setting of CQ-resistant $P$. falciparum, these error rates might estimate the risk of inappropriate therapy. Rapid diagnostic tests (RDT) do not solve this problem either. The risk of false negative $P$. falciparum with RDT (varying from $2 \%$ at $>5000$ parasites $\mu \mathrm{L}^{-1}$ to $25 \%$ at $<500$ parasites $\mu \mathrm{L}^{-1}[80]$ ) can be considered the risk of receiving ineffective chloroquine therapy where $P$. vivax, $P$. malariae or P. ovale also occur.

\section{Concluding remarks}

Several key factors have contributed to the neglect of vivax malaria in research. Until very recently, the global burden of disease has almost certainly been underestimated by a very large margin $[2,3]$. The broadly held perception of vivax malaria as a benign infection diminished its standing with regard to research priorities. Finally, the inability to maintain $P$. vivax in continuous culture in vitro undoubtedly hindered research in the laboratory, and forced most research investments into relatively inaccessible, costly and difficult endeavors in endemic areas.

The highlighted gaps in understanding put forth in this review represent front-line research questions (Box 1). Although expanding laboratory work and interest would undoubtedly yield valuable tools against vivax malaria, the urgent need is for clinical and epidemiological studies.

\section{Box 1. Oustanding questions for $P$. vivax research}

Is $P$. vivax a complex of species?

Does $P$. vivax cause a falciparum-like severe illness syndrome?

Does $P$. vivax have virulent strains?

What are the demographic or clinical risk factors for severe disease?

What is the mechanism of chloroquine activity?

How widespread is resistance to chloroquine?

What is the mechanism of resistance to chloroquine?

What are effective alternative therapies for chloroquine-resistant strains?

What is the mechanism of primaquine activity against hypnozoites? Is primaquine monotherapy effective against hypnozoites? What is the mechanism of primaquine toxicity in G6PD deficiency? How can G6PD deficiency be determined at the point of care? How widespread is resistance to primaquine?

How should resistance to primaquine be documented? What is the mechanism of resistance to primaquine?

What are effective alternative therapies against relapse?

How can late relapse in travelers be prevented?

How can $P$. vivax be diagnosed accurately?
Those studies would give greater direction and impact to laboratory studies. Grasping when, how and how often vivax malaria causes severe illness and what drugs most effectively cure the severely ill, represent the first important steps in addressing the neglect of this parasite.

\section{Acknowledgements}

The author gratefully acknowledges the advice and assistance of Chansuda Wongsrichanalai in Bangkok and Jason Maguire in Portsmouth, Virginia in compiling and analyzing the data on microscopy errors. W.R.J. Taylor in Hanoi and Professor Carol Sibley in Seattle provided thoughtful reviews of the manuscript.

\section{References}

1 Guerra, C.A. et al. (2006) Mapping the global extent of malaria in 2005. Trends Parasitol. 22, 353-358

2 Hay, S.I. et al. (2004) The global distribution and population at risk of malaria: past, present, and future. Lancet Infect. Dis. 4, 327-336

3 Mendis, K. et al. (2001) The neglected burden of Plasmodium vivax malaria. Am. J. Trop. Med. Hyg. 64S, 97-106

4 Miller, L.H. (1983) Malaria. In Infectious Diseases (3rd edn) (Hoeprich, P.D., ed.), pp. 1253-1264, Harper \& Row Publishers

5 Kochar, D.K. et al. (2005) Plasmodium vivax malaria. Emerg. Infect. Dis. 11, 132-134

6 Beg, M.A. et al. (2002) Cerebral involvement in benign tertian malaria. Am. J. Trop. Med. Hyg. 67, 230-232

7 Saleri, N. et al. (2006) Acute respiratory distress syndrome in Plasmodium vivax malaria in traveler returning from Venezuela. J. Travel Med. 13, 112-113

8 Kumar, S. et al. (2007) P. vivax complicated by shock and ARDS. Scand. J. Infect. Dis. 39, 255-256

9 Spudick, J.M. et al. (2005) Diagnostic and therapeutic pitfalls associated with primaquine-tolerant Plasmodium vivax. J. Clin. Microbiol. 43, 978-981

10 Habib, A.G. and Singh, K.S. (2004) Respiratory distress in nonimmune adults with imported malaria. Infection 32, 356-359

11 Carlini, M.E. et al. (1999) Vivax malaria complicated by adult respiratory distress syndrome. Clin. Infect. Dis. 28, 1182-1183

$12 \mathrm{Koh}, \mathrm{K} . \mathrm{H}$. et al. (2004) A retrospective study of malaria infections in an intensive care unit of a general hospital in Malaysia. Singapore Med. J. $45,28-36$

13 Mehta, K.S. et al. (2001) Severe acute renal failure in malaria. J. Postgrad. Med. 47, 24-26

14 Pakash, J. et al. (2003) Acute renal failure in Plasmodium vivax malaria. J. Assoc. Physicians India 51, 265-267

15 Ozen, M. et al. (2006) Cerebral malaria owing to Plasmodium vivax: case report. Ann. Trop. Paediatr. 26, 141-144

16 Barcus, M.J. et al. Demographic risk factors for severe and fatal Vivax and Falciparum malaria among hospital admissions in Northeastern Indonesian Papua. Am. J. Trop. Med. Hyg. (in press)

17 Kotwal, R.S. et al. (2005) An outbreak of malaria in US Army Rangers returning from Afghanistan. J. Am. Med. Assoc. 293, 212-216

18 Mohapatra, M.K. et al. (2002) Atypical manifestations of Plasmodium vivax malaria. Indian J. Malariol. 39, 18-25

19 Makkar, R.P. et al. (2002) Plasmodium vivax malaria presenting with severe thrombocytopenia. Braz. J. Infect. Dis. 6, 263-265

20 Tanious, M.A. et al. (2001) Acute respiratory distress syndrome complicating Plasmodium vivax malaria. Crit. Care Med. 29, 665667

21 Kakar, A. et al. (1999) Profound thrombocytopenia in Plasmodium vivax malaria. Diagn. Microbiol. Infect. Dis. 35, 243-244

22 Gockel, H.R. et al. (2006) Spontaneous splenic rupture in tertian malaria. Infection $34,43-45$

23 Ozsoy, M.F. et al. (2004) Splenic complications in malaria: report of two cases from Turkey. J. Med. Microbiol. 53, 1255-1258

24 Lawn, S.D. et al. (2003) Case reports: pernicious complications of benign tertian malaria. Trans. R. Soc. Trop. Med. Hyg. 97, 551553

25 Kaur, D. et al. (2007) Unusual presentation of Plasmodium vivax malaria with severe thrombocytopenia and acute renal failure. J. Trop. Pediatr. 53, 210-212 
26 Anstey, N.M. et al. (2007) Lung injury in vivax malaria: pathophysiological evidence for pulmonary vascular sequestration and post-treatment alveolar-capillary inflammation. J. Infect. Dis. $195,589-596$

27 Collins, W.E. et al. (2004) A retrospective examination of reinfection of humans with Plasmodium vivax. Am. J. Trop. Med. Hyg. 70, 642-644

28 Luxemburger, C. et al. (1997) The epidemiology of severe malaria in an area of low transmission in Thailand. Trans. R. Soc. Trop. Med. Hyg. 91, 256-262

29 Muhlberger, N. et al. (2004) Epidemiology and clinical features of vivax malaria imported to Europe: sentinel surveillance data from TropNetEurop. Malaria J. 3, 5

30 Leder, K. et al. (2004) Malaria in travelers: a review of the GeoSentinel surveillance network. Clin. Infect. Dis. 39, 1104-1112

31 Newman, R.D. et al. (2004) Malaria-related deaths among U.S. travelers 1963-2001. Ann. Intern. Med. 141, 547-555

$32 \mathrm{Li}$, J. et al. (2001) Geographic subdivision of the range of the malaria parasite Plasmodium vivax. Emerg. Infect. Dis. 7, 35-42

33 Baird, J.K. (2004) Resistance to chloroquine by Plasmodium vivax. Antimicrob. Agents Chemother. 48, 4075-4083

34 Rieckmann, K.H. et al. (1989) Plasmodium vivax resistance to chloroquine? Lancet 2, 1183-1184

35 Ratcliff, A. et al. Therapeutic response of multidrug-resistant Plasmodium falciparum and $P$. vivax to chloroquine and sulfadoxine-pyrimethamine in southern Papua, Indonesia. Trans. $R$. Soc. Trop. Med. Hyg. (in press)

36 Tan-ariya, P. et al. (1995) Clinical response and susceptibility in vitro of Plasmodium vivax to the standard regimen of chloroquine in Thailand. Trans. R. Soc. Trop. Med. Hyg. 89, 426-429

37 Looareesuwan, S. et al. (1999) Chloroquine sensitivity of Plasmodium vivax in Thailand. Ann. Trop. Med. Parasitol. 93, 225-230

38 Congpuong, K. et al. (2002) Sensitivity of Plasmodium vivax to chloroquine in Sa Kaeo Province, Thailand. Acta Trop. 83, 117-121

39 Tasanor, O. et al. (2006) Clinical-parasitological response and in-vitro sensitivity of Plasmodium vivax to chloroquine and quinine on the western border of Thailand. Trans. R. Soc. Trop. Med. Hyg. 100, 410418

40 Vijaykadga, S. et al. (2004) Assessment of therapeutic efficacy of chloroquine for vivax malaria in Thailand. Southeast Asian J. Trop. Med. Pub. Health 35, 566-569

41 Nandy, A. et al. (2003) Monitoring the chloroquine sensitivity of Plasmodium vivax from Calcutta and Orissa, India. Ann. Trop. Med. Parasitol. 97, 215-220

42 Dunne, M.W. et al. (2005) A double-blind, randomized study of azithromycin compared to chloroquine for the treatment of Plasmodium vivax malaria in India. Am. J. Trop. Med. Hyg. 73, $1108-1111$

43 Valecha, N. et al. (2006) Therapeutic efficacy of chloroquine in Plasmodium vivax from areas with different epidemiological patterns in India and their Pvdhfr gene mutation pattern. Trans. $R$. Soc. Trop. Med. Hyg. 100, 831-837

44 Kurcer, M.A. et al. (2006) The decreasing efficacy of chloroquine in the treatment of Plasmodium vivax malaria in Sanliurfa, southeastern Turkey. Ann. Trop. Med. Parasitol. 100, 109-113

45 Kurcer, M.A. et al. (2004) Efficacy of chloroquine in the treatment of Plasmodium vivax malaria in Turkey. Ann. Trop. Med. Parasitol. 98, 447-451

46 Phan, G.T. et al. (2002) Artemisinin or chloroquine for blood stage Plasmodium vivax malaria in Vietnam. Trop. Med. Int. Health 7, 858-864

47 Maguire, J.D. et al. (2006) Mefloquine is highly efficacious against chloroquine-resistant Plasmodium vivax and Plasmodium falciparum malaria in Papua, Indonesia. Clin. Infect. Dis. 42, 1067-1072

48 Ruebush, T.K. et al. (2003) Chloroquine-resistant Plasmodium vivax malaria in Peru. Am. J. Trop. Med. Hyg. 69, 548-552

49 Alvarez, G. et al. (2006) Efficacy of three chloroquine-primaquine regimens for treatment of Plasmodium vivax malaria in Colombia. Am. J. Trop. Med. Hyg. 75, 605-609

50 Harinasuta, T. et al. (1985) Trials of mefloquine in vivax and of mefloquine plus fansidar in falciparum malaria. Lancet i, 885888

51 Dixon, K.E. et al. (1985) A clinical trial of mefloquine in the treatment of Plasmodium vivax malaria. Am. J. Trop. Med. Hyg. 34, 435-437
52 Alcantara, A.K. et al. (1985) A comparative clinical study of mefloquine and chloroquine in the treatment of vivax malaria. Southeast Asian J. Trop. Med. Public Health 16, 534-538

53 Pukrittayakamee, S. et al. (2004) Therapeutic responses to antimalarial and antibacterial drugs in vivax malaria. Acta Trop. $89,351-359$

54 Baird, J.K. et al. (1995) Treatment of chloroquine-resistant Plasmodium vivax with chloroquine and primaquine or halofantrine. J. Infect. Dis. 171, 1678-1682

55 Taylor, W.R. et al. (2001) Chloroquine/doxycycline combination versus chloroquine alone and doxycycline alone for the treatment of Plasmodium falciparum and Plasmodium vivax malaria in northeastern Irian Jaya, Indonesia. Am. J. Trop. Med. Hyg. 64, $223-228$

56 Lacy, M.D. et al. (2002) Atovaquone/proguanil therapy for Plasmodium falciparum and Plasmodium vivax malaria in Indonesians who lack clinical immunity. Clin. Infect. Dis. 35, e92-e95

57 Collins, W.E. et al. (2000) Adaptation of a chloroquine-resistant strain of Plasmodium vivax from Indonesia to New World monkeys. Am. J. Trop. Med. Hyg. 62, 491-495

58 Obaldia, N., 3rd et al. (1997) WR238605, chloroquine, and their combinations as blood schizonticides against a chloroquine-resistant strain of Plasmodium vivax in Aotus monkeys. Am. J. Trop. Med. Hyg. $56,508-510$

59 Cooper, R.D. et al. (1994) The efficacy of WR238605 against the blood stages of a chloroquine-resistant strain of Plasmodium vivax. Trans. $R$. Soc. Trop. Med. Hyg. 88, 691-692

60 Tasanor, O. et al. (2002) An in vitro system for assessing the sensitivity of Plasmodium vivax to chloroquine. Acta Trop. 83, 49-61

61 Russell, B.M. et al. (2003) Simple in vitro assay for determining the sensitivity of Plasmodium vivax isolates from fresh human blood to antimalarials in areas where P. vivax is endemic. Antimicrob. Agents Chemother. 47, 170-173

62 Tasanor, O. et al. (2006) Clinical-parasitological response and in vitro sensitivity of Plasmodium vivax to chloroquine and quinine on the western border of Thailand. Trans. R. Soc. Trop. Med. Hyg. 100, $410-418$

63 Sattabongkot, J. et al. (2006) Establishment of a human hepatocyte line that supports in vitro development of the exo-erythrocytic stages of the malaria parasites Plasmodium falciparum and P. vivax. Am. J. Trop. Med. Hyg. 74, 708-715

64 Baird, J.K. and Hoffman, S.L. (2004) Primaquine therapy for malaria. Clin. Infect. Dis. 39, 1336-1345

65 Brueckner, R.P. et al. (2000) 8-Aminoquinolines. In Antimalarial Chemotherapy: Mechanisms of Action, Resistance and New Directions in Drug Discovery (Rosenthal, P.J., ed.), pp. 123-151, Humana Press Inc

66 Bates, M.D. et al. (1990) In vitro effects of primaquine and primaquine metabolites on exoerthrocytic stages of Plasmodium berghei. Am. J. Trop. Med. Hyg. 42, 532-537

67 Baird, J.K. et al. (1986) Effects of nine synthetic putative metabolites of primaquine on activity of the hexose monophosphate shunt in human red blood cells in vitro. Biochem. Pharmacol. 35, 10991106

68 Bolchoz, L.J. et al. (2001) Primaquine-induced hemolytic anemia: formation and hemotoxicity of the arylhdroxylamine metabolite 6-methoxy-8-hydryoxylaminoquinoline. J. Pharmacol. Exp. Ther. $297,509-515$

69 White, N.J. (1985) Pharmacokinetics of antimalarial drugs. Clin. Pharmacokinet. 10, 187-215

70 Schmidt, L.H. et al. (1977) Radical cure of infections with Plasmodium cynomolgi: A function of total 8-aminoquinoline dose.Am. J. Trop. Med. Hyg. 26, 1116-1128

71 Edgcomg, J.H. et al. (1950) Primaquine, SN 13272, a new curative agent in vivax malaria: a preliminary report. J. Natl Malar. Soc. 9, 285-292

72 Alving, A.S. et al. (1955) Potentiation of the curative action of primaquine in vivax malaria by quinine and chloroquine. J. Lab. Clin. Med. 46, 301-306

73 Baird, J.K. et al. (2003) Primaquine for prevention of malaria in travelers. Clin. Infect. Dis. 37, 1659-1667

74 Hill, D.R. et al. (2006) Primaquine: report from CDC expert meeting on malaria chemoprophylaxis I. Am. J. Trop. Med. Hyg. 75, 401-415 
75 Schwartz, E. et al. (2003) Delayed onset of malaria - implications for chemoprophylaxis in travelers. N. Engl. J. Med. 349, 15101516

76 Schwartz, E. and Regev-Yochay, G. (1999) Primaquine as prophylaxis for malaria for nonimmune travelers: A comparison with mefloquine and doxycycline. Clin. Infect. Dis. 29, 502-506

77 Mayxay, M. et al. (2001) Identification of cryptic coinfection with Plasmodium falciparum in patients presenting with vivax malaria. Am. J. Trop. Med. Hyg. 65, 588-592
78 Siripoon, N. et al. (2002) Cryptic Plasmodium falciparum parasites in clinical P. vivax blood samples from Thailand. Trans. R. Soc. Trop. Med. Hyg. 96, 70-71

79 McKenzie, F.E. et al. (2003) Dependence of malaria detection and species diagnosis by microscopy on parasite density. Am. J. Trop. Med. Hyg. 69, 372-376

80 Forney, J.R. et al. (2001) Malaria rapid diagnostic devices: performance characteristics of the ParaSight $F$ device determined in a multisite field study. J. Clin. Microbiol. 39, 2884-2890 